\title{
Design and Implementation of Multilayer GIS Framework in Natural Resources Management: Red Sea Area
}

\author{
Thowiba E. Ahmed $\left(\mathbb{D},{ }^{1}\right.$ K. M. Kheiralla $\left(\mathbb{D},{ }^{2}\right.$ Fatima Rayan Awad Ahmed $\left(\mathbb{D},{ }^{3}\right.$ \\ Rashid A. Saeed, ${ }^{4}$ and Hesham Alhumyani ${ }^{4}$ \\ ${ }^{1}$ Computer Science Dept, College of Science Humanities-Jubail, Imam Abdulrahman Bin Faisal University, \\ Jubail 35811, Saudi Arabia \\ ${ }^{2}$ Department of Geophysics, Alneelain University, Khartoum, Sudan \\ ${ }^{3}$ Computer Science Dept., College of Computer Engineering and Science, Prince Sattam Bin Abdulaziz University, \\ Al-Kharj 11942, Saudi Arabia \\ ${ }^{4}$ Department of Computer Engineering, College of Computers and Information Technology, Taif University, P.O. Box 11099, \\ Taif 21944, Saudi Arabia
}

Correspondence should be addressed to Thowiba E. Ahmed; teahmed@iau.edu.sa

Received 15 February 2021; Revised 18 March 2021; Accepted 31 March 2021; Published 20 April 2021

Academic Editor: Ahmed Mostafa Khalil

Copyright (C) 2021 Thowiba E. Ahmed et al. This is an open access article distributed under the Creative Commons Attribution License, which permits unrestricted use, distribution, and reproduction in any medium, provided the original work is properly cited.

\begin{abstract}
This study aims to create an integrated geographical information system (GIS) database of natural resources represented by mining activities in the Red Sea area in Sudan. GIS is a vital tool to help the decision-makers in managing and classifying these resources in terms of quantity and quality within the concept of sustainable development. The paper extracts some models of investment map indicators. In addition to that, it conducts a study and research aimed at developing a mineral resources management and discovering and identifying the new areas of mineral wealth in GIS database. The motivation of this study stems from the fact that countries with these types of wealth can greatly grow their gross domestic product (GDP) through the optimum management and governance. Most of the least development countries (LDC) can focus on the search for alternative natural resources (beside other conventional resources, i.e., agriculture) to support their economy. Red Sea region is one of the great regions full of natural and mineral resources (specifically gold and minerals), beside its strategic location on the way of most of the global trade transaction path. This paper designs and implements GIS multiple database layers. The multiple layers were modelled to overcome the technical difficulties that result from processing of large quantities of tempospatial information. The database was built by using an Oracle database system due to its capability of multilayer design.
\end{abstract}

\section{Introduction}

The availability of mineral wealth as natural resources has three main features, which are relative scarcity, variation of uses, and possibility of being mixed with other resources to produce the same commodity or other commodities. The scarcity means insufficiency or shortness of available resources to satisfy the needs and desires of people. The scarcity is seen clearly when comparing the available resources with the required quantities of resources to satisfy the needs of the population.
The emergence of concept of sustainable development has increased the social, economic, and political importance of resources in the economies of countries [1-3]. Dajian stated that since UN approved the sustainable development goals (SDGs) globally for the coming 10 years (2016-2030), sustainability has become one of the main pillars for development and fundamental perception to lead the national and international social and economic developments. Conferring to this concept, consolidating the integrative review research on the methodologies, theories, and empirical literature of maintainable development have been a deliberately vital issue and mission [4]. 
The rationale and environmental management, maintaining and development of resources, and increase of available quantities of resources will be realized soon. The realization is through listing all existing mineral resources and laying down the necessary plans distributed among their different uses, laying down the programs for development and increase of these resources, adopting all necessary measures to organize and monitor how to utilize these georesources in the manner confirming rationalization of resources [5], and avoiding any evidence of misuse of resources and protecting them from all kinds of risks leading to deterioration or depletion of resources without any passive impacts on the environment.

Sudan has a rich energy and mineral resources base, and the development of the mining sector has been described as the single most vital lever for economic diversification, job creation, and government revenue growth [6]. The ability of the government to support and regulate the sector is paramount as significant investments and operations are about to begin domestically and internationally [7]. Mining regulators will play an important role in Sudan's journey towards being a modern and independent country by enhancing transparency through the regularization of the mining industry and thus empowering Sudan to make most of its mineral wealth.

The mining activities in Sudan have the potential to play a vital role in Sudan's future for jobs creation, generates royalties, and taxies to local governments and bring about much sustainable development infrastructures, thereby closing the poverty gap. A system for monitoring adherence to mining standards as well as environmental, social, technical, and financial compliance with international best practices and Sudanese laws and customs [8] is essential in order to ensure contract compliance and the sustainability of production.

This includes the use of reliable baseline data along with adequate preparation and transfer of know-how. The Red Sea Area Municipal Government offers state-of-the-art earth observation software to produce baseline data supporting compliance monitoring and monitoring of mine production activities in mining concession areas.

In realistic terms, the project includes introducing a computerized, rule-based management system with GIS features which caters to mineral titles for the lifecycle. The framework must also ensure that the processes for title administration comply with the applicable laws and regulations [9]. Within the cadastral organization, the development will be followed by operational and technological capacity building activities. It is expected that the resulting enhanced and open administration of mining titles would make the mining industry more desirable to investment by the private sector, mining, and mining sector [10-13].

The remainder of this paper is organized as follows: in Section 2, the mineral and natural resources in the Red Sea area are discussed. In Section 3, the methods and materials of the general GIS framework have been described. The related works are discussed in Section 4. The results and discussions are presented in Section 5. Finally, concluding remarks are given in Section 6.

\section{Related Works}

Geographic information system (GIS) is a specific combination of management structure, computer software, procedural mechanisms, processors, peripherals, institutions, and individuals to collect, store, modulate, manipulate, evaluate, and display geographically relevant data that are extensively deliberated in resolving sophisticated humanrelated problems, for example, Thowiba et al. [14], Wu et al. [15], and $\mathrm{Li}$ and $\mathrm{Li}$ [16]. There are several studies dealing with the design and implementation of GIS in the management of natural and mineral resources for sustainable development, almost all of which have approved that GISs are important for decision-making in support of natural resource development.

Ibrahim [17] proposed mineral asset arranging and administration data framework which incorporates the method of building the framework, framework design, and improvement stage, as well as the determination of development devices. Planning the most capacities of framework and working environment moreover has been outlined (shown in Figure 1).

Aklıbaşınd [18] presented the utilizations of geographic information systems (GIS) technique in the management of natural and mineral resources and shows with data evidence how they have grown rapidly. GIS is the primary method for large-scale spatiotemporal data analysis and is usually used as a medium for communicating landscape scale research results to all stakeholders.

Also, Mahyar and Nykänen [19] studied the use and utilization areas of geographic information system (GIS) increase every day due to both enabling easiness in storing, updating, grouping, analyzing, correlating, and mapping of data about evaluation factors in planning studies and having quite low error margin depending on the accuracy of stored data. Also, Khalid and Deshmukh [20] discussed the mineral and natural resources with potential aiming to use GIS techniques as an efficient methodology to delineate area under study for more investigations of mineral deposits.

Moran in [21] made a database of a little zone with not already indicated objective. The paper delivered a number of outline layers emphasizing the strategy and the capacity of making any number of overlays or combinations of layers. Moreover, the time and toll taken that included in creating these layers have been assessed. Figure 2 shows the stream chart of the proposed database.

\section{Mineral and Natural Resources in the Red Sea Area}

The Red Sea area lies in the eastern part of Sudan (between longitudes of 18-23 northeast) covering an area of $218,887 \mathrm{~km}$ [22-25]. The state is bordering the state of Kassala and Eritrea in the south, state of River Nile in the west, the Red Sea in the East, and Egypt in the North. The Red Sea area is surrounded in the northeastern parts by the Red Sea Hills. Figure 3 shows the area of the study. The Red Sea Hills are a mostly continuous mountain chain in northeastern Sudan which parallel the Red Sea coast from 


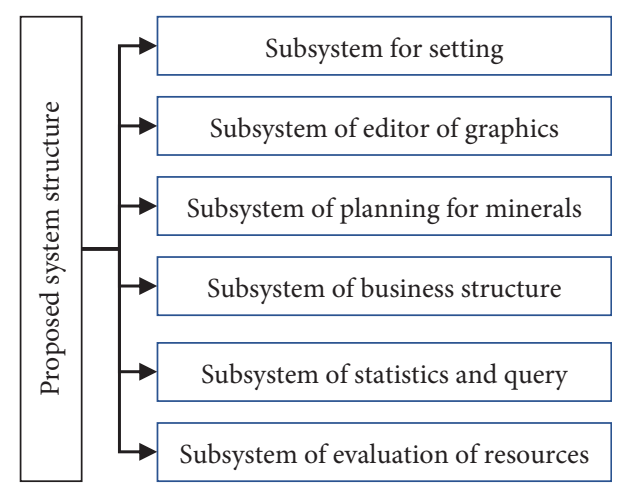

FIgURe 1: Proposed function of the system structure.

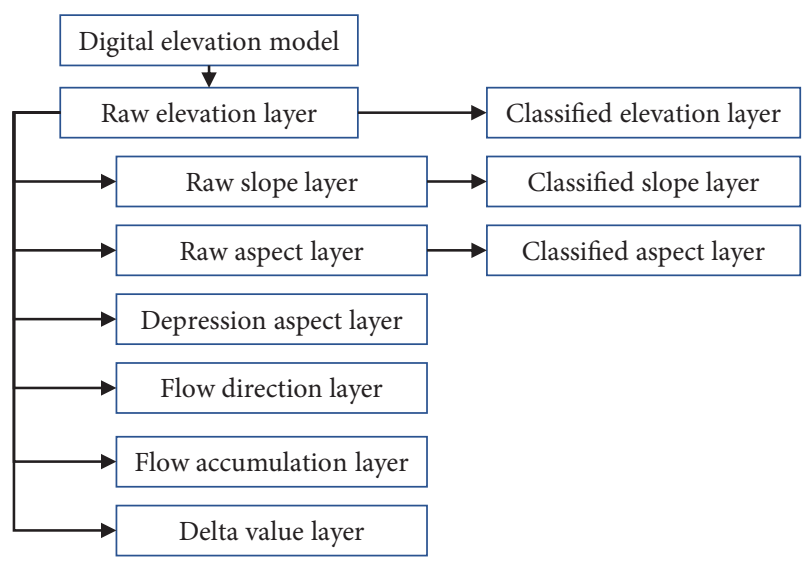

FIGURE 2: Proposed multilayer GIS database for natural resources by Khalid.

the Egyptian border in the north to Eritrea in the south. The mountains are a consequence of uplift relating to the East African Rift system and subsequent graben faulting which produced the Red Sea and coastal environments that fringe the mountains in a $20-50 \mathrm{~km}$ wide plains area [26].

Since the Pharaonic era, eastern Sudan and the chain of Red Sea Mountains are known with the existence of all kinds of metal so that more than $90 \%$ of mining projects mineral exploration activities have been established in the eastern parts of Sudan, where there is a huge belt extending from the northern borders to the eastern parts of the Nile and up to the southern borders of the eastern state of the Red Sea [27]. The Red Sea area is rich in so many mineral resources including copper, gold, boron, arsenic, chrome, zinc, copper, silver, lead, and manganese and building materials such as granite, gypsum, and stone salt, as reported by Mohamed Suliman in 2015 [28-30].

Since the independence of Sudan, the government has given great attention to mining of gold but even one of the reasons for the Turkish invasion to Sudan was the search for gold in the mountains of Beni Shangoul. Mining studies have shown that 60 gold mining sites are located in the Jebbit region, in addition to billions of tons of iron, ilmenite, rutile, and barite, which are used in aircraft bodies and high-quality paints industries.
Although metals and building materials cover most of the state, exploration activities are limited in Ariab Gold Mining Co. and Red Rock Iron Mining Co., as well as the activities of Prison Authority work in extraction of salts besides the business of some small companies operating in extraction of gypsum and manganese as reported by Wenger et al. [31].

In accordance with the study's objectives, this paper sets out the results of a review of the relevant data available upon the Red Sea area together with a newly undertaken GIS spatial data processing that has been undertaken to build investment maps and mineralogical information and to identify those parts of the Red Sea area which are considered to be more important and prospective for commercial mineralization [32].

The most significant mineral occurrences and deposits discovered in the Red Sea area to date are associated with the greenstone-ophiolite areas. These can be summarized from south to north as follows:

(i) Derudeb Belt: greenstone-like suite with coppergold occurrences near Derudeb

(ii) Ariab Belt: host to the productive Ma Mancha VMS (volcanogenic massive sulphide) deposits at Hassai, etc., extending northeast to gold and copper occurrences in the Nakaseib block and Port Sudan

(iii) Gebeit Belt: greenstone-like suite in which the Gebeit gold deposit occurs

(iv) Hamissana Belt: host to gold occurrences at Onur, Eikwan, and Oyo

\section{Methodology}

The general model of the proposed database is illustrated in Figure 4, where the process will start with the geographical data collections through remote sensing system. The received data and information form the remote sensing network would be described and interpreted in multilayer database. The coordinated data would be analyzed with stochastic methods; finally a GIS report using graphical user interface (GUI) can be achieved.

The work will be done by using mainly geo-information coupled with GIS techniques and data are entered as effective tools for data collection and processing. Different type of geoinformatics data covering whole mining concessions area in the Red Sea area will be acquired and loaded in database.

These will include Landsat (TM with 7 bands and 8-band ETM) (SPOT, IRS, ASTER, RADAR, IKONOS, and Quick bird), geological and structural maps, topographic maps, geophysical maps, geochemical results, and estimate of reserve which are recognized to be useful for mineral mapping and compilation of mining geodatabase in the Red Sea area. All geoinformatics data will be acquired and processed.

The secondary data on mining, minerals, geology, infrastructure, and so forth will be obtained from different sources. Example of secondary information for collection and review prior to and during building database for mining sector is summarized in Table 1. 


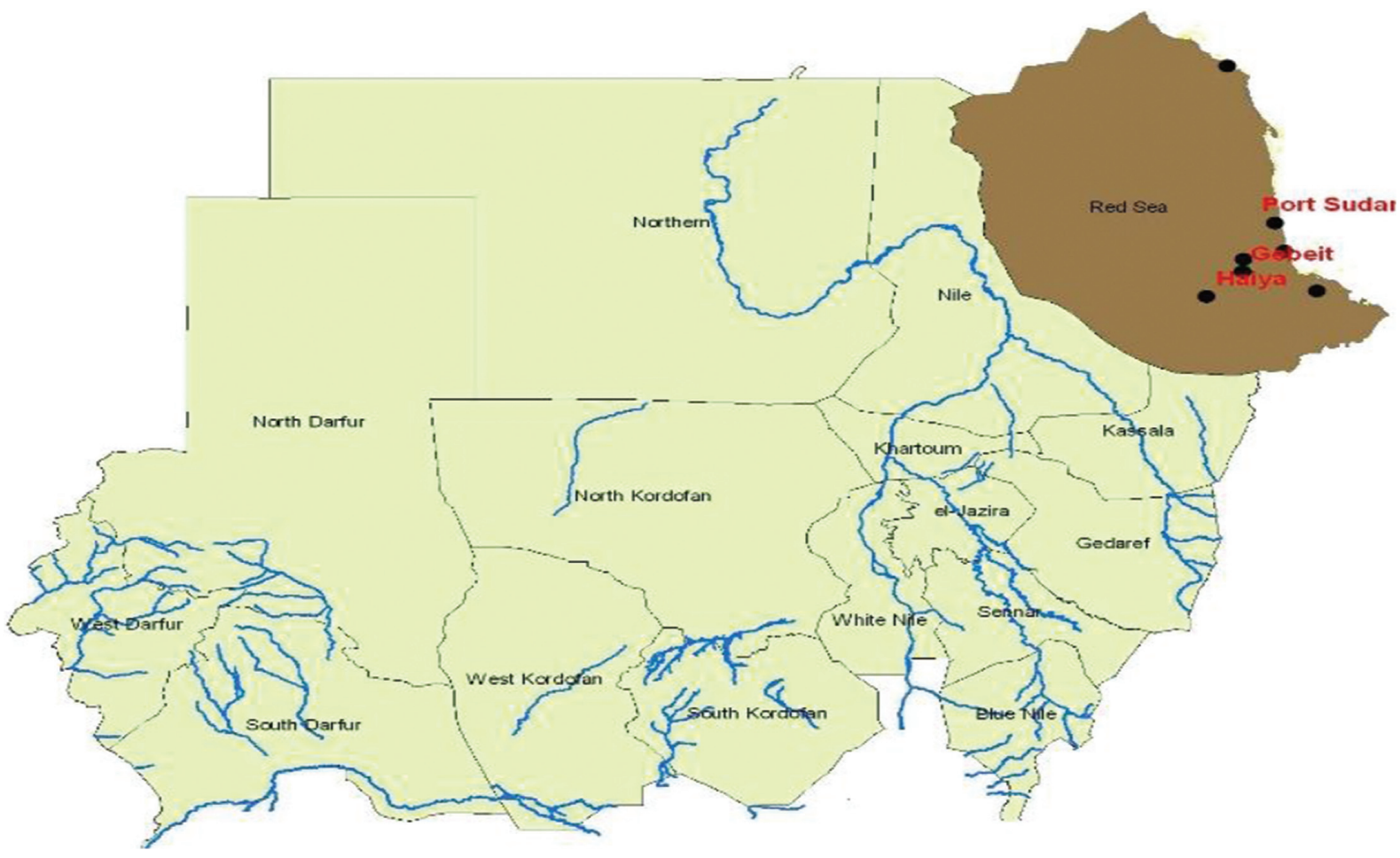

Figure 3: Study area.

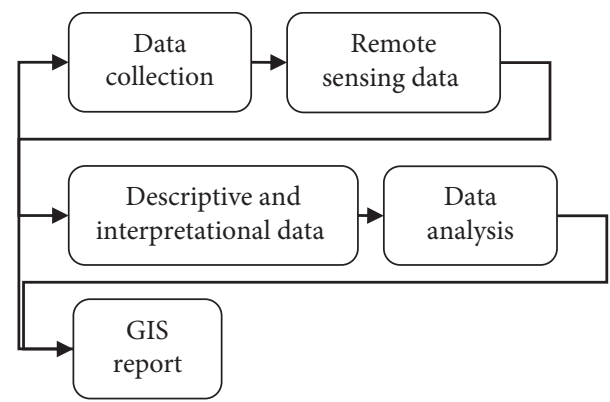

FIgURE 4: Generalized model of the proposed multilayer GIS database.

The nature of the assignment requires interaction, correspondence, and interlinkage between the different layer components as shown in the flow chart in Figure 5. As shown in the flow chart, work plan starts from correspondence with the client, selection of the team members, and discussion with them to ensure clarity of duties required from each member.

The data determined the location of the study through the GPS and satellite images/pictures which enhance the use of data in the GIS. We have designed the main model of the basic map in the study area and determined all features of the system in the map. Establishment of a database using Oracle software describes the objects and determines their location in the map. We used inquiries, telephone calls, interviews, and emails to collect the necessary data. The database has been provided with the necessary tools to manage the environment professionally with the data and information ready for any analysis using the mathematical calculation such as network analysis so that it will be easy for all processes of the system.

\section{Design and Implementation of the Database}

The phase of building databases is the phase responsible for analysis process of units included in configuration of the system such as description of inputs [33,34], analysis of processors and outputs such as tables, files, input screens, and inquiries, and analysis of the maps used in the system in preparation for linking the system with the GIS. There has been no systematic mineral exploration of the Red Sea area and by comparison with the geology of the Red Sea Hills situated to the north of Port Sudan there are few reliable records of mineral investigations.

Most of the information pertaining to the study area and its surroundings is present in historic geological mapping details from surveys performed during the early 20th century, which resulted in the production of $1: 250,000$ scale geological maps (from north to south) of the Port Sudan area (sheet no. 46-A), the Sinkat area (sheet no. 46-E), and the Derudeb area (sheet no. 46-I) together with their accompanying memoirs. This study has been able to access all Red Sea area topo-sheet, geological maps, and thematic data and has had to restrict its findings accordingly [4].

In addition, various technical papers and bulletins of the Geological Research Authority of Sudan (GRAS) contain individual references to mineral occurrences in the general vicinity of the Red Sea area. A list of databases have been developed to provide information on the geology and mineralization of the Red Sea area together with key 
TABLE1: Geodatabase used to build the investment map of mineral resources.

\begin{tabular}{|c|c|c|}
\hline & Categories & Contents \\
\hline 1 & $\begin{array}{l}\text { Maps, satellite images, and } \\
\text { photos }\end{array}$ & $\begin{array}{l}\text { Maps: geology, structure, soil, terrain, land-use, vegetation, watersheds and water points, planning; } \\
\text { time series satellite images (TM, ETM + 7, Landsat 8, ASTER, ALOS, SPOT, Geoeye, high-resolution } \\
\text { image, etc.); aerial photographs }\end{array}$ \\
\hline 2 & Geophysical data & $\begin{array}{c}\text { Airborne geophysical data: gravity and magnetic ground mining geophysical data: electromagnetic, } \\
\text { induce polarization, self-potential, magnetic, gravity, resistivity, etc. }\end{array}$ \\
\hline \multirow[t]{2}{*}{3} & Geochemical data & $\begin{array}{l}\text { Geochemical sampling data: soil, stream, chip, trench samples, etc. Drilling data: core sample analysis } \\
\text { data. }\end{array}$ \\
\hline & Mining & $\begin{array}{l}\text { Existing plans, projects, and programs; mining systems information; information (presence and } \\
\text { extent) on local and introduced practices for mining management, mining process, and procedure }\end{array}$ \\
\hline 4 & Geology & Geological data from different sources \\
\hline 5 & Water resources & Existing water resources information (surface and underground water) \\
\hline 0 & $\begin{array}{l}\text { Reports and other relevant } \\
\text { documents }\end{array}$ & \\
\hline
\end{tabular}
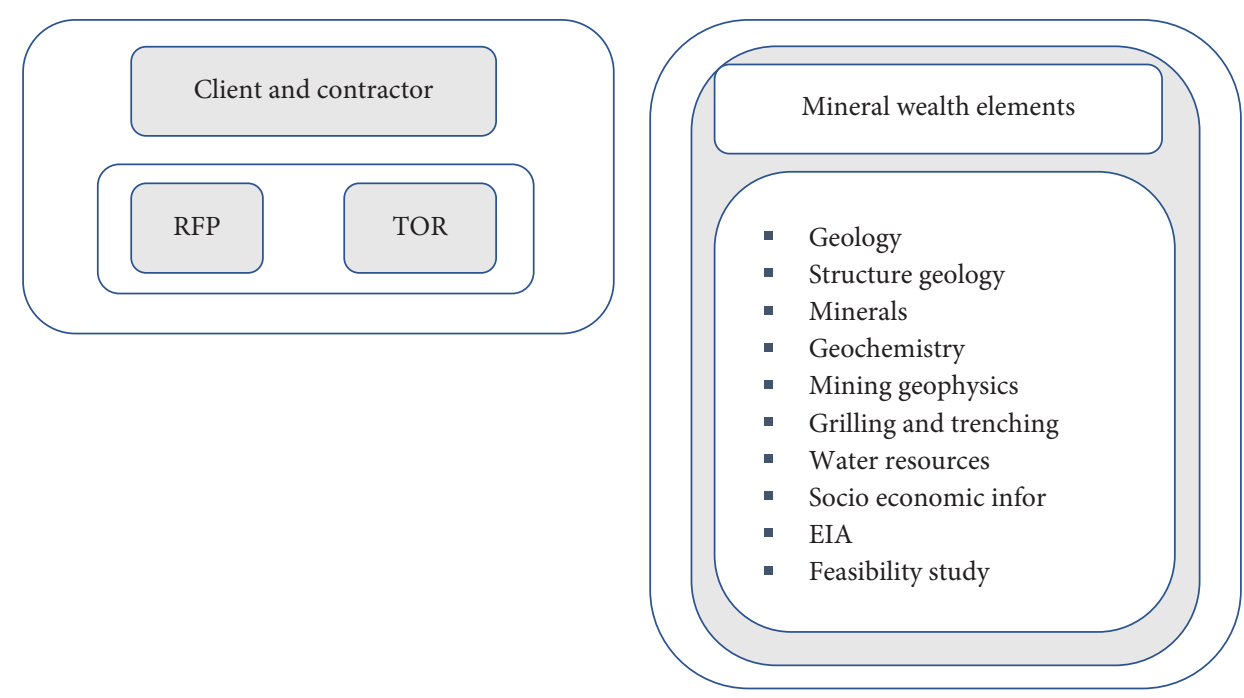

(a)

(b)
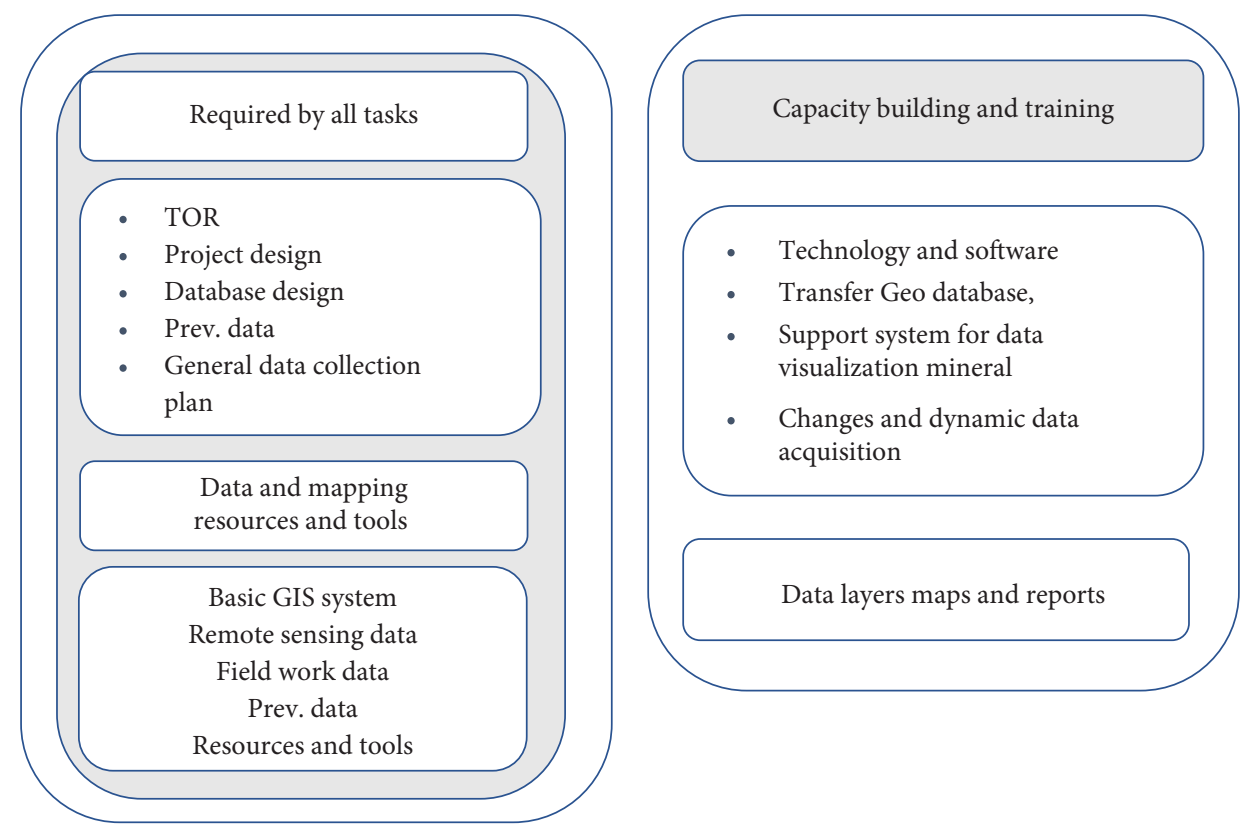

(c)

FIgURE 5: Continued. 

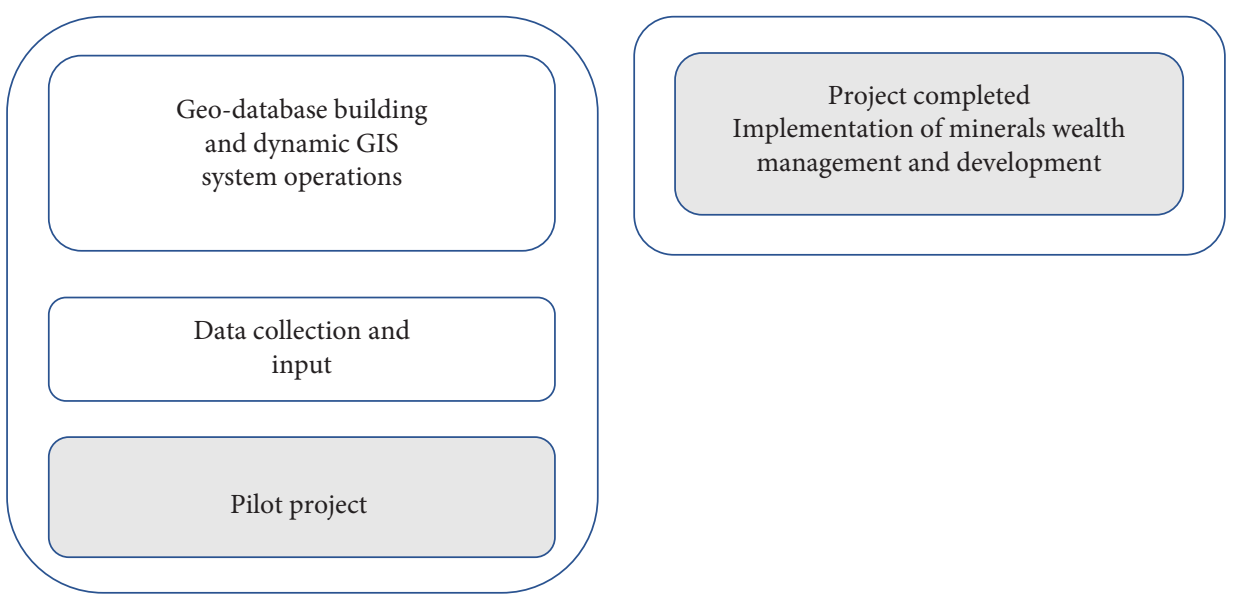

(e)

(f)

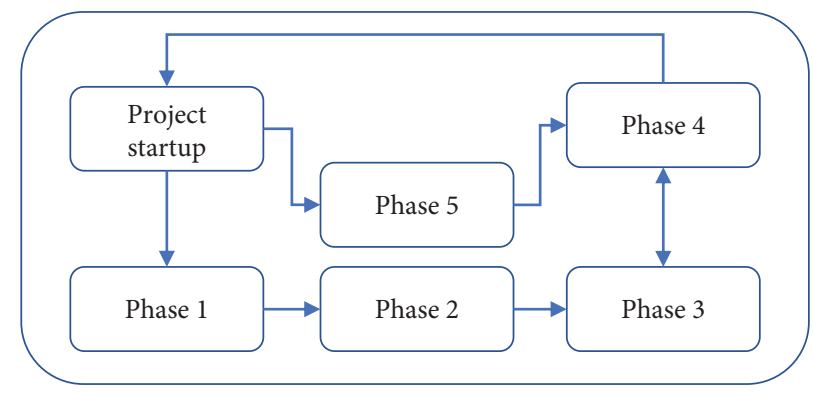

(g)

Figure 5: Generalization of GIS database implementation diagram. (a) Project startup. (b) Phase 1. (c) Phase 2. (d) Phase 3 . (e) Phase 4. (f) Phase 5. (h) The whole GIS project diagram and flow chart.

information upon type deposits situated elsewhere along the Red Sea Hills [5].

Public Records: Generalized and detailed accounts of the geology and mineralization of the Sudanese Red Sea Hills (and relevant areas in Egypt, Eritrea, and Saudi Arabia) have been acquired from digital and Internet sources including public records of exploration companies active in Sudan and surrounding countries. Archived Records: As part of this study, archived records of the geology and mineralization of Sudan have been interrogated and inspected from the following sources:

(i) AMCO Robertson: records of the Minex and Greenwich Resources programs in the northern Red Sea Hills

(ii) Fugro Robertson: World Bank sponsored 1:1 million scale geological maps of Sudan published in 1988

(iii) British Geological Survey: general references and 1 : 250,000 geological maps of the Derudeb area (sheet no. $46-\mathrm{I})$

(iv) GRAS: generalized geological maps of the Red Sea area and some individual technical papers on some areas in the Red Sea area

The database interfaces are designed by using Oracle database system. Figure 6 shows some of data entry interfaces.

\section{Mineral Resources Maps Designing by GIS}

The digital mineral resources maps are designed in several file formats (such as shape files which will take the shp extension). Each file contains a single layer layout of the geographic map of the system, and the proposed geographic information system needs to have a geographic map containing the main infrastructures, water sources, medical care, and potential mineral wealth, where each component of the abovementioned components represents the shape in layer to which it follows [24, 35].

Also, we shall need that each layer must contain a layer of those composed as attributes to represent an identification number for it so that we can connect the data of the map with the database tables of the system which contained the data of the mineral resources in the Red Sea area. We present hereunder samples of maps which we have designed for these purposes in Figure 7.

\section{Result and Discussion}

By using Oracle database management system and GIS techniques, we have produced the maps showing the pools of the mineral resources areas of a particular region showing the current use of land and conclude the future usage maps. We may also utilize the available information on these mineral resources in order to create relations between them. We have taken advantage of these techniques in the work of some models of investment indicators in the state. 


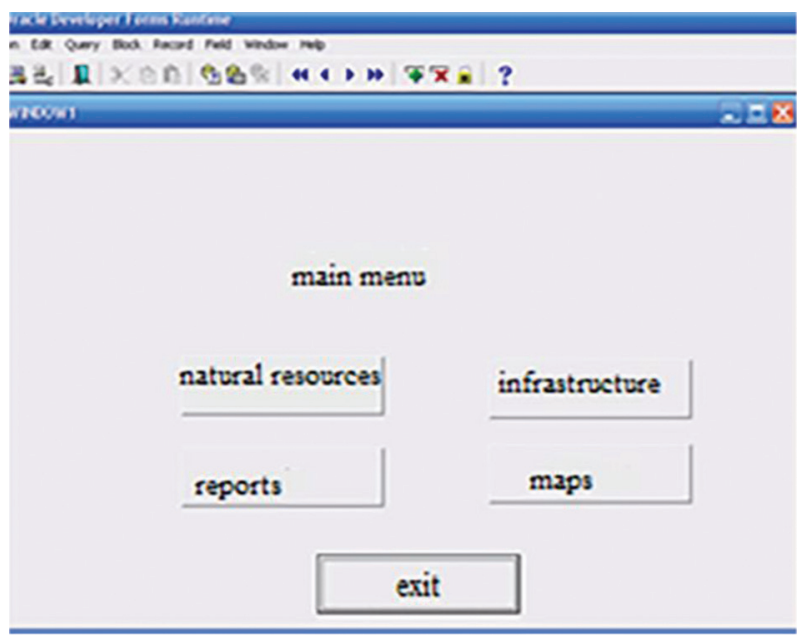

(a)

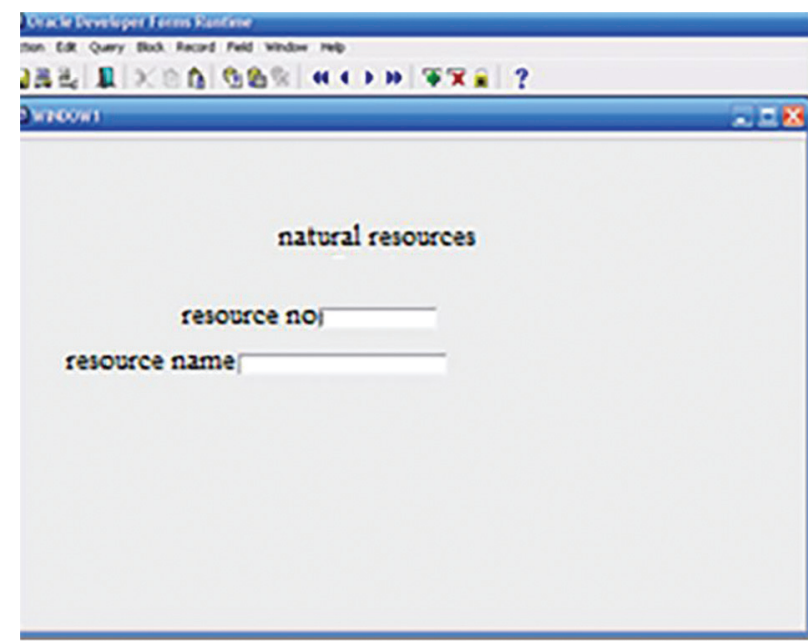

(b)

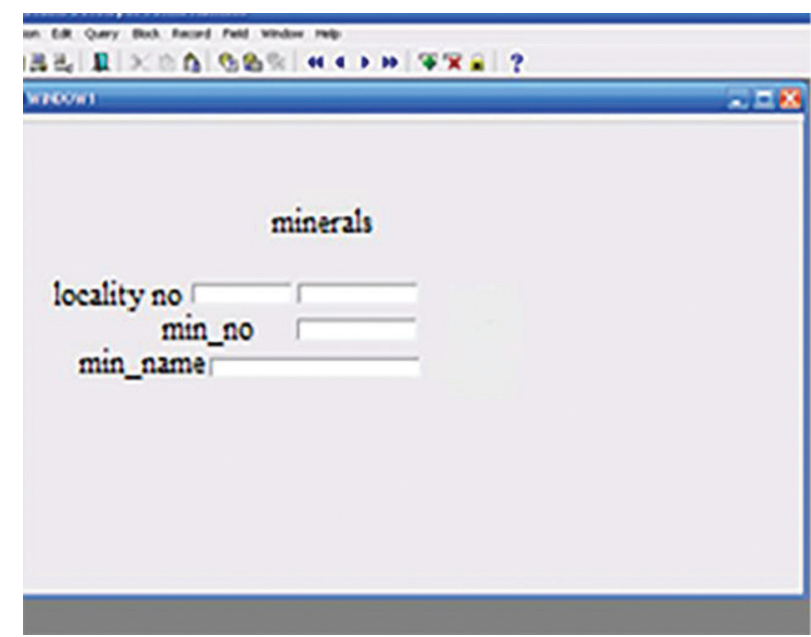

(c)

Figure 6: The system web-based interface. (a) Main screen. (b) Natural resources data entry. (c) Mineral recourses data entry screen.

Despite such an absence of definitive known occurrences within the Red Sea area, it is pertinent to record that there are recent reports of mineralization deposits being discovered in the Red Sea area. These mineralization occurrences are discussed in further detail as follows:

(1) Aymad copper occurrence (approximately $19^{\circ} 25^{\prime} \mathrm{N} /$ $36^{\circ} 46^{\prime} \mathrm{E}$ ). The Aymad occurrence is in Haya terrain.

(2) Abu Samar manganese occurrence (approximately $\left.17^{\circ} 58^{\prime} \mathrm{N} / 36^{\circ} 19^{\prime} \mathrm{E}\right)$.

(3) Khor Knushnateib/Tohamiyam copper occurrence (approximately $18^{\circ} 18^{\prime} \mathrm{N} / 36^{\circ} 32^{\prime} \mathrm{E}$ ).

(4) Tagoteb copper occurrence (approximately $17^{\circ} 33^{\prime} \mathrm{N} /$ $\left.36^{\circ} 14^{\prime} \mathrm{E}\right)$.

(5) Kass gold occurrence (approximately $18^{\circ} 19^{\prime} \mathrm{N} /$ $\left.36^{\circ} 11^{\prime} \mathrm{E}\right)$. It occurs about $4 \mathrm{~km}$ east of Kass railway station.

(6) Sabidana gold occurrence in Derudeb belt.

(7) Other occurrences: numerous gold and copper showings also occur along the southwestward's extension of the Derudeb belt. Several copper showings are also reported from the Karora belt which straddles the border zone with Eritrea.

Based on the data extracted from database and maps, we have selected from the map shown in Figure 8 the area of Haya terrain and its surrounding as a model area for mining activities because this area is rich in several types of metal and minerals such as marble, cobalt, gold, and silver [26]. This area is also close to the main national road and it is a densely populated area $(358,285$ persons according to last census in 2009), where manpower could be easily found.

There are also some health facilities scattered around in the area such as Shadiab health center which is only four kilometers away from Haya, and another primary healthcare center is also located four kilometers to the south of the city of Haya [27]. A hospital is also found just about 49 kilometers away. Several water sources (water yards, open shaft wells, and hand pumps) are also available at very close distances, a matter giving this area an investment privilege. 


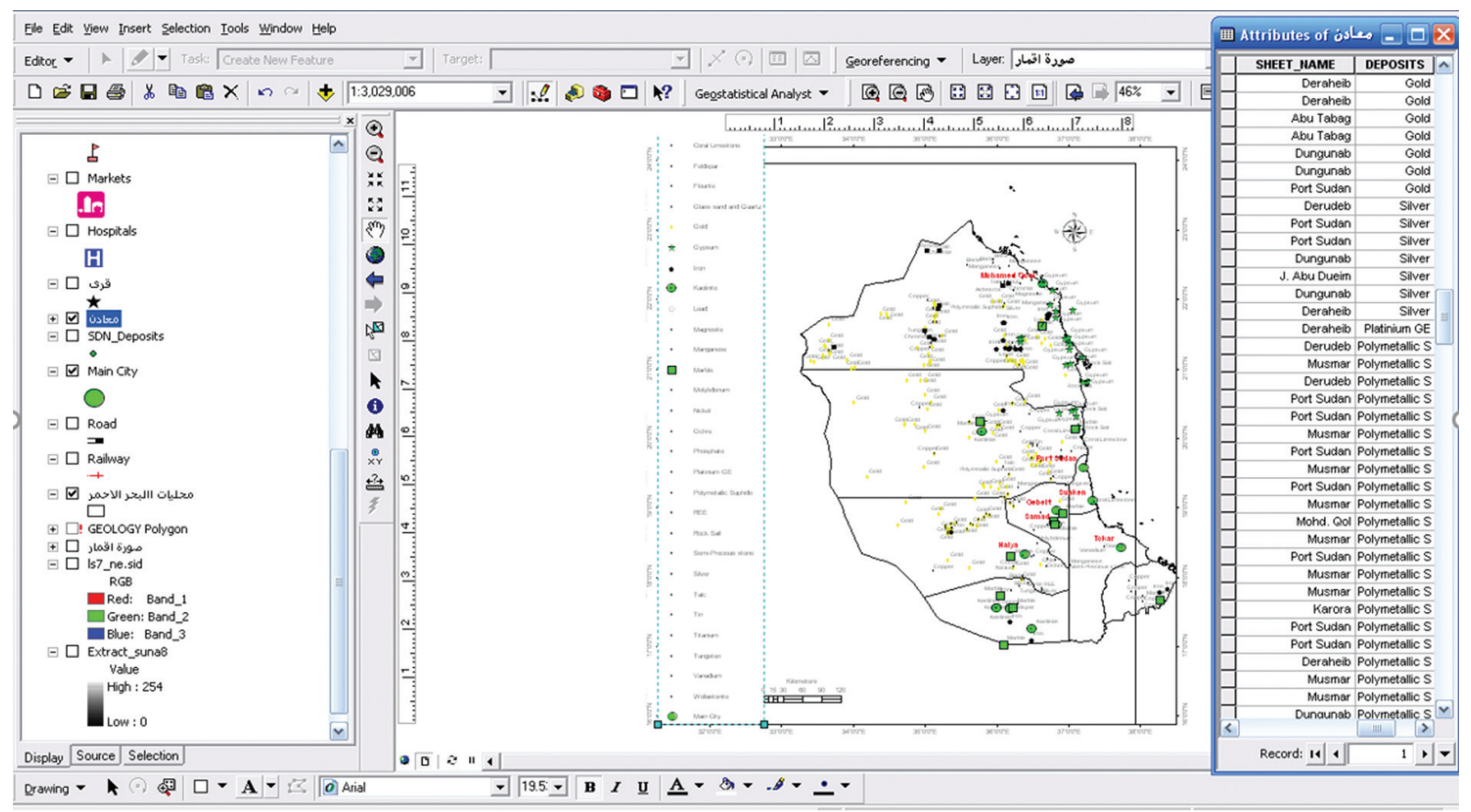

FIgUre 7: A map showing the mineral resources in the Red Sea area.

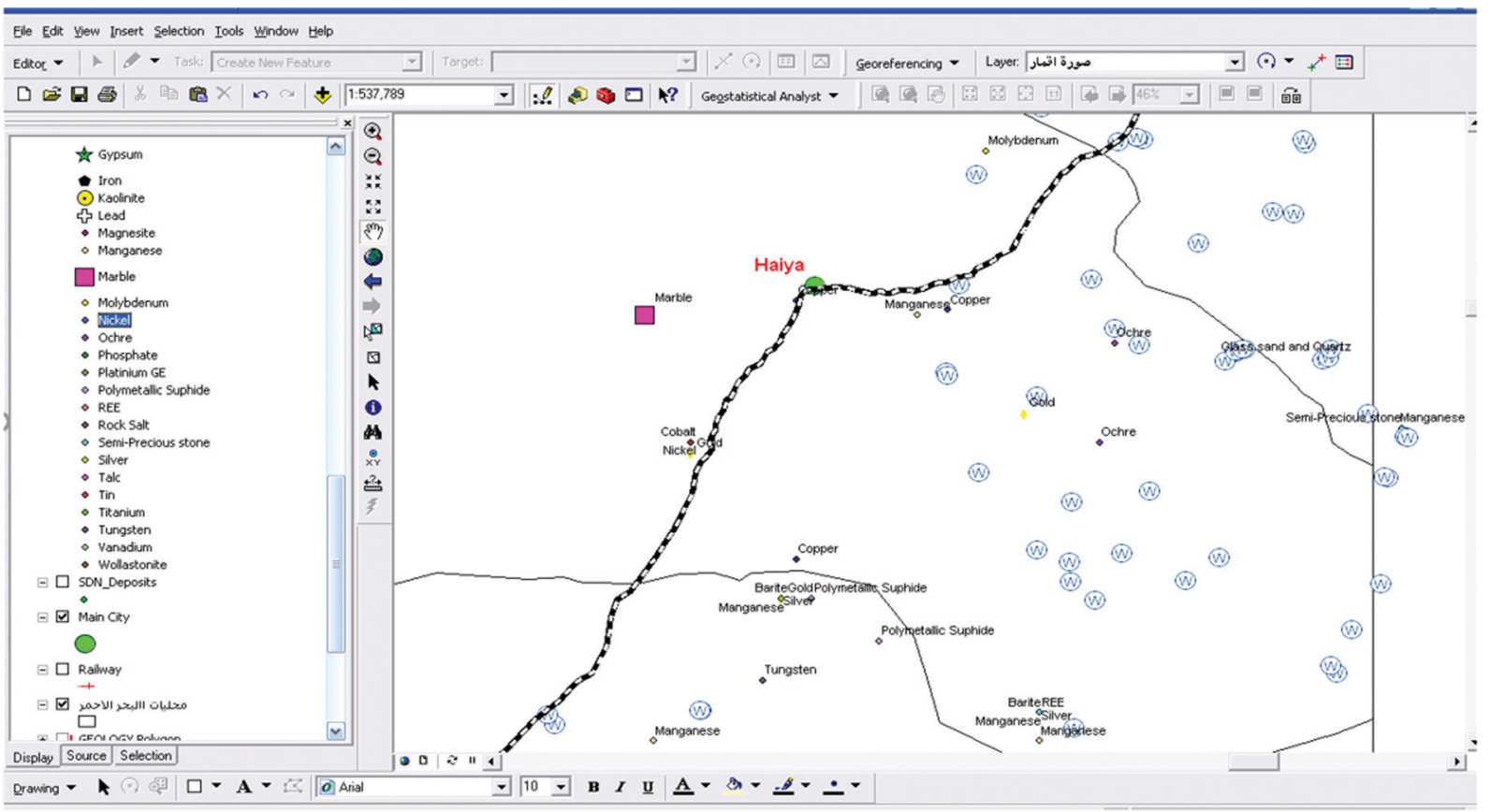

FIgURE 8: A map showing an ideal mining area.

\section{Conclusions}

The motivation of this study stems from the fact that countries with these types of wealth can greatly increase their gross domestic product through the optimum management and governance. Most of the least development countries can focus on the search for alternative natural resources (beside other conventional resources, i.e., agriculture) to support their economy. Geographical information is vital for abstracting and presenting data to benefit from results to be extracted for decision-making purposes which are considered as the most important factor in management of natural resources. Preparing such database is quite important for governance to be utilized in future investment or any possible alternative uses of mineral resources management and plan. In this paper, the database classified by places was built to facilitate the creation of an investment map in the future. All features and privileges were made available by the 
paper for the area under study. A work is needed in the future for possibility features in the database for converting it to an electronic geographic information system to be part of the e-government published by authorities. Also, the produced multilayers in the geodatabase need to be stacked for injecting data from remote sensing, land surveyor, and Internet of things (IoT) devices for sustainability and applicability to be integrated with other systems.

\section{Data Availability}

The data used to support the findings of this study are available from the corresponding author upon request.

\section{Conflicts of Interest}

The authors declare that there are no conflicts of interest regarding the publication of this paper.

\section{Acknowledgments}

This research was supported by Taif University Researchers Supporting Project number (TURSP-2020/216), Taif University, Taif, Saudi Arabia.

\section{References}

[1] S. Zhang, K. Yang, and Y. Cao, "GIS-based rapid disaster loss assessment for earthquakes," IEEE Access, vol. 7, 2019.

[2] L. Wang, R. Wang, X. Li, and S. Jia, "Simulation analysis on the impact of different filling gases on the temperature rise of C-GIS," IEEE Transactions on Components, Packaging and Manufacturing Technology, vol. 9, no. 10, 2019.

[3] Y. Wang, J. Yan, Q. Sun, J. Li, and Y. Zhou, "A MobileNets convolutional neural network for GIS partial discharge pattern recognition in the ubiquitous power internet of things context: optimization, comparison, and application," IEEE Access, vol. 7, 2019.

[4] A. Ehrensperger, S. W. von Dac, and F. Kakridi Enz, "Geographic information technologies for natural resource management," Bern University of Applied Sciences, Bern, Switzerland, Focus No 3/07, 2007, https://web.inforesources. bfh.science/pdf/focus07_3_e.pdf.

[5] M. J. Nusayba, "GIS-based environmental and ecological planning for sustainable development," 2017, https://www. geospatialworld.net/article/gis-based-environmental-andecological-planning-for-sustainable-development/.

[6] M. Li, M. Lenzen, F. Keck et al., "GIS-based probabilistic modeling of BEV charging load for Australia," IEEE Transactions on Smart Grid, vol. 10, no. 4, 2019.

[7] E. S. Ali Ahmed and R. A. Saeed, "A survey of big data cloud computing security," International Journal of Computer Science and Software Engineering (IJCSSE), vol. 3, no. 1, pp. 78-85, 2014.

[8] T. Wen, Y. Zhao, X. Fan, Q. Zhang, N. Shimomura, and W. Chen, "Insulation characteristics of GIS bus with conductive protrusion attached to the high-voltage electrode under lightning impulses with different wavefront times," IEEE Transactions on Dielectrics and Electrical Insulation, vol. 26, no. 6, 2019.

[9] Z. Zhang, W. Guo, M. Li, and W. Yu, "GIS-supervised building extraction with label noise-adaptive fully convolutional neural network," IEEE Geoscience and Remote Sensing Letters, vol. 17, no. 12, 2020.

[10] D. Zhu, "Researches from global Sustainable Development Goals (SDGs) to sustainability science-based on the object subject process framework," Chinese Journal of Population Resources and Environment (CJPRE), vol. 15, no. 1, 2017.

[11] L. Kevin, Oracle Database11G the Complete References, McGraw-Hill Companies, New York, NY, USA, 2009.

[12] M. Abdelgadir and A. Rashid, "Saeed and abuagla babiker, "cross layer design approach for efficient data delivery based on IEEE 802.11P in vehicular ad-hoc networks (VANETS) for city scenarios"' International Journal on Ad Hoc Networking Systems (IJANS), vol. 8, no. 4, 2018.

[13] W. Kainz, Geographic Information Science (GIS) Cartography and Geoinformation Department of Geography and Regional Research, University of Vienna, Vienna, UK, 2004.

[14] E. H. Thowiba, A. M. Alsamni, and K. M. Khiralla, "Use GIS for generating an educational-map with the contexts of UNESCO-education for sustainable development programs-a case study in Red Sea area-Sudan," International Journal of Computer Applications (IJCA), vol. 113, no. 4, pp. 8-22, 2015.

[15] J. Wu, J. Chen, and Y. Ren, "GIS enabled service site selection: environmental analysis and beyond," Information Systems Frontiers, vol. 13, no. 3, p. 337, 2011.

[16] H.-F. Li and J.-G. Li, "Research on mineral resources planning and management information system based-on GIS technology," ISPRS International Journal of Geo-Information, vol. 7-C4, 2009.

[17] M. S. Ibrahim, Artisanal Mining in Sudan - Opportunities, Challenges and Impacts-UNCTAD 17th Africa Oilgasmine, Extractive Industries and Sustainable Job Creation, Khartoum, Sudan, 2015.

[18] M. Aklıbaşında and Y. Bulut, "Analysis of terrains suitable for tourism and recreation by using geographic information system (GIS)," Environmental Monitoring and Assess, vol. 186, p. 5711, 2014.

[19] M. Yousefi and V. Nykänen, "Introduction to the special issue: GIS-based mineral potential targeting," Journal of African Earth Sciences, vol. 128, pp. 1-4, 2017.

[20] A. Khalid and S. Deshmukh, "Evaluation and mapping of wind energy potential over southern part of India using ANN and GIS approach," in Proceedings of the 2018 International Conference and Utility Exhibition on Green Energy for Sustainable Development (ICUE), Phuket, Thailand, October 2018.

[21] S. Fiorini, "Book chapter human-environment interactions volume 1 of the series human-environment interactions pp 97," Change in Natural Resource Management: An Experiment with "Participatory GIS", 2019.

[22] W. L. Gorr and K. S. Kurland, GIS Tutorials1, Basic Workbook Supplement for ArcGIS 10.2, Esri Press, Redland, CF, USA, 2014.

[23] R. A. Saeed, R. A. Mokhtar, J. Chebil, and A. H. Abdallah, "TVBDs coexistence by leverage sensing and geo-location database," in Proceedings of IEEE International Conference on Computer \& Communication Engineering (ICCCE2012), pp. 33-39, Kuala Lump, Malaysia, July 2012.

[24] Get Started with ArcGIS Onlinehttps://learn.arcgis.com/en/ projects/get-started-with-arcgis-online/Copyright 2017 Esri.

[25] R. Mokhtar and R. A. Saeed, "Conservation of mobile data and usability constraints," in Cyber Security Standards, Practices and Industrial Applications: Systems and Methodologies, Z. Junaid and M. Athar, Eds., pp. 40-55, IGI Global, PA, USA, 2011. 
[26] Ji Li, X. Pei, X. Wang, D. Yao, Yi Zhang, and Y. Yue, "Transportation mode identification with GPS trajectory data and GIS information," Tsinghua Science and Technology, vol. 26 , no. $4,2021$.

[27] A. L. Duncan and D. H. Lach, "Privileged knowledge and social change: effects on different participants of using geographic information systems technology in natural resource management," Environmental Management, vol. 38, no. 2, p. 267, 2006.

[28] E. Sayed Ali and R. A. Saeed, "BigData distributed systems management," in Networking for Big Data Book, S. Yu and X. Lin, Eds., pp. 57-71, 2015.

[29] D. Beslija, D. Gorenc, M. Muratovic, and M. Kapetanovic, "Enhanced method for pressure rise calculation in SF6 GIS due to fault arcs," IEEE Transactions on Power Delivery, vol. 35 , no. 4,2020 .

[30] G. P. Thomas: Sudan: Mining, Minerals and Fuel Resourceshttp://www.azomining.com/Article.aspx?ArticleID=191.

[31] P. Wenger, M. Beltle, S. Tenbohlen, U. Riechert, and G. Behrmann, "Combined characterization of free-moving particles in HVDC-GIS using UHF PD, high-speed imaging, and pulse-sequence analysis," IEEE Transactions on Power Delivery, vol. 34, no. 4, 2019.

[32] W. Fang, C. Wang, X. Chen et al., "Corrections to recognizing global reservoirs from Landsat 8 images: a deep learning approach," IEEE Journal of Selected Topics in Applied Earth Observations and Remote Sensing, vol. 12, no. 9, 2019.

[33] L. Ashdown and K. Tom, Oracle Database Concepts, $11 g$ Release, vol. 2, pp. 11-12, 2014.

[34] X. Han, J. Li, L. Zhang, P. Pang, and S. Shen, "A novel PD detection technique for use in GIS based on a combination of UHF and optical sensors," IEEE Transactions on Instrumentation and Measurement, vol. 68, no. 8, 2019.

[35] K. M. Hassouna, "Developing a natural resource database for geographic information system," Master Thesis, Virginia Polytechnic Institute, Blacksburg, Virginia, 1997. 